\title{
PENGENALAN ZAT ADITIF PADA MAKANAN DAN DAMPAKNYA TERHADAP KESEHATAN DI SMA NEGERI I BELIMBING MUARA ENIM PROVINSI SUMATERA SELATAN
}

\author{
Ita Emilia $^{1 *}$, Andi Arif Setiawan², Yunita Panca Putri ${ }^{1}$, Marmaini $^{1}$, Dewi Rosanti ${ }^{1}$ \\ Dwi Warsari ${ }^{1}$, Syaiful Eddy ${ }^{1}$, Syamsul Rizal $^{1}$, Dewi Novianti ${ }^{1}$, Dian Mutiara ${ }^{1}$, Nur Haziza ${ }^{1}$ \\ ${ }^{\text {I} P r o g r a m ~ S t u d i ~ B i o l o g i, ~ F a k u l t a s ~ M a t e m a t i k a ~ d a n ~ I l m u ~ P e n g e t a h u a n ~ A l a m, ~ U n i v e r s i t a s ~ P G R I ~ P a l e m b a n g, ~}$ \\ Palembang, Indonesia \\ ${ }_{2}^{2}$ Program Studi Fisika, Fakultas Matematika dan Ilmu Pengetahuan Alam, Universitas PGRI Palembang, \\ Palembang, Indonesia \\ *Penulis korespondesi: yunita_pp12@yahoo.co.id
}

\begin{abstract}
Abstrak
Penggunaan zat aditif pada makanan yang tidak bijaksana dapat menimbulkan berbagai masalah kesehatan, antara lain alergi, radang tenggorokan, keracunan, kelainan pertumbuhan, bahkan dapat menimbulkan kematian. Sehubungan dengan hal tersebut, untuk mengurangi dampak negatif yang ditimbulkan dari pemakaian zat aditif makanan perlu mendapat perhatian dari insan akademis dari perguruan tinggi untuk menyampaikan penyuluhan mengenai pengenalan zat aditif pada makanan dan dampaknya terhadap kesehatan terutama pada siswa dan siswi SMA Negeri 1 Belimbing Muara Enim Provinsi Sumatera Selatan. Kegiatan ini secara keseluruhan dapat dikatakan berjalan baik dan berhasil, dilihat dari antusias siswa-siswa dalam memberikan pertanyaan, ketercapaian target jumlah peserta penyuluhan (100\%), dan kemampuan siswa-siswi dalam menjawab dengan benar lembar pertanyaan (86,6\%). Hal ini menunjukkan bahwa dengan adanya kegiatan ini memberikan dampak positif kepada siswa-siswi dalam memberikan informasi dan menumbuhkan kesadaran mengenai dampak negatif dari mengkonsumsi makanan atau jajanan di sekolah yang mengandung zat aditif makanan.
\end{abstract}

Kata kunci: Zat Aditif; Makanan; Dampak Kesehatan.

\begin{abstract}
The use of additives in foods that are not wise can cause various health problems, including allergies, strep throat, poisoning, growth abnormalities, can even cause death. In connection with this, to reduce the negative impacts arising from the use of food additives need attention from academic people from universities to delivered counseling about the introduction of additives in food and their impact on health, especially for students of SMA Negeri 1 Belimbing Muara Enim, South Sumatra Province. This activity as a whole can be said to work well and successfully, seen from the enthusiasm of students in giving questions, the target number of extension participants (100\%), and the ability of students to correctly answer the question sheets (86.6\%). This shows that the existence of this activity has a positive impact on students in providing information and raising awareness about negative effects of consuming food or snacks in schools that contain food additives.
\end{abstract}

Keywords: Additives; Food; Health Effects.

\section{PENDAHULUAN}

Makanan merupakan salah satu kebutuhan pokok yang sangat penting dalam kehidupan manusia, karena seluruh masyarakat tanpa terkecuali merupakan konsumen pangan. Kebutuhan makanan yang sehat akan terpenuhi jika makanan yang kita konsumsi memiliki syarat-syarat yang sehat yang dibutuhan oleh tubuh. Adapun syarat-syarat makanan sehat yang aman dikonsumsi meliputi bahan makanan harus bergizi seimbang, higenis dan bersih tidak mengandung kuman bibit penyakit atau racun, penyimpanan dan pengolahan makanan harus tepat, mudah dicerna, mengandung cukup air, serta bentuknya menarik dan rasanya enak (Wisnu, 2003).

Penggunaan bahan tambahan atau zat aditif pada makanan semakin meningkat, terutama setelah adanya penemuan penemuan termasuk keberhasilan dalam mensintesis bahan kimia baru yang lebih praktis, lebih murah, dan lebih mudah diperoleh. Penambahan bahan tambahan/zat aditif ke dalam makanan merupakan hal yang dipandang perlu untuk meningkatkan mutu suatu produk sehingga mampu bersaing di pasaran. Secara umum bahan tambahan/aditif ini dapat dibedakan menjadi dua yaitu: (1) aditif sengaja yaitu aditif yang 
secara sengaja ditambahkan untuk meningkatkan konsistensi, cita rasa, mengendalikan keasaman/kebasaan, dan memantapkan bentuk dan rupa; (2) aditif tidak sengaja yaitu aditif yang memang telah ada dalam makanan (walaupun sedikit) sebagai akibat dari proses pengolahan (Winarno, 1992 dalam Siaka, 2009).

Penyelenggaraan keamanan pangan dilakukan salah satunya melalui pengaturan terhadap bahan tambahan pangan. Dalam Undang-Undang Republik Indonesia Nomor 18 tahun 2012 pasal 75 ayat 1 dicantumkan juga bahwa "Setiap orang yang memproduksi pangan untuk diedarkan dilarang menggunakan bahan apapun sebagai bahan tambahan pangan yang dinyatakan terlarang atau melampaui ambang batas maksimal yang telah ditetapkan dan/atau bahan yang dilarang digunakan sebagai bahan tambahan pangan". Disebutkan juga bahwa "pemerintah menetapkan lebih lanjut bahan yang dilarang dan atau dapat digunakan sebagai bahan tambahan pangan dalam kegiatan atau proses produksi pangan serta ambang batas maksimalnya.." Bahan tambahan pangan lebih rinci lagi kemudian diatur didalam Peraturan Menteri Kesehatan Republik Indonesia Nomor 033 tahun 2012 tentang Bahan Tambahan Pangan (Fitri, 2014).

Zat adiktif makanan atau food aditive merupakan senyawa atau campuran berbagai senyawa yang sengaja ditambahkan kedalam makanan dan terlibat dalam proses pengolahan, pengemasan, atau penyimpanan dan bukan merupakan bahan utama (Indra, 2003). Berdasarkan fungsinya jenis zat adiktif yang boleh digunakan untuk makanan terdiri dari pemberi aroma, penyedap rasa, pengembang, pemutih, pematang tepung, zat pemucat, zat pengasam, antioksidan, pengawet, termasuk pemanis dan pewarna (Karunia, 2013).

Kesehatan adalah keadaan sejahtera dari badan, jiwa dan sosial yang memungkinkan setiap orang hidup produktif secara sosial dan ekonomi, setiap orang mempunyai hak yang sama dalam memperoleh derajat kesehatan yang optimal. Sebagaimana disebutkan dalam UU kesehatan No 23 tahun 1992 pasal 16 bahwa peningkatan dan pemantapan upaya kesehatan diselenggarakan melalui 15 macam kegiatan salah satunya penggunaan zat aditif (Departemen Kesehatan RI, 1992). Dalam produksi pangan olahan untuk tujuan penggunaan zat aditif dalam meningkatkan kualitas bahan pangan tidak mungkin dihindari terutama dalam pengolahan makanan. Produsen sering memberikan bahan tambahan makanan dari zat kimia salah satunya yaitu pengawet makanan. Tujuan penggunaan bahan pengawet adalah untuk menghambat atau menahan laju pertumbuhan mikroorganisme seperti bakteri, kapang dan khamir pada makanan sehingga dapat meningkatkan produk olahan, meningkatkan cita rasa, memperbaiki tekstur dan perubahan warna (Departemen Pertanian, 2002).
Penggunaan zat aditif pada makanan yang tidak bijaksana dapat menimbulkan berbagai masalah kesehatan misalnya keracunan, kerusakan syaraf, ginjal, hati, cacat kelahiran, gangguan gastroenteritis, kejangkejang, anomalia kaki, kelainan pertumbuhan, kemandulan bahkan kematian (Yamin $d k k$., 2018). Ancaman yang memungkinkan terjadi jika terus menerus terpapar (mengkonsumsi) makanan atau minuman yang mengandung zat aditif berbahaya adalah keracunan system syaraf pusat, perdarahan pada beberapa bagian tubuh, anomalia kaki, kelainankelainan pertumbuhan, kangker, kemandulan, cacat kelahiran, gangguan gastroenteristis yang berat, kerusakan ginjal, hati, kejang-kejang, bahkan kematian Telah terjadi kontroversi yang signifikan terkait resiko dan keuntungan dari zat aditif pada makanan (Downs, 2008 dalam Japa dkk., 2019). Keracunan yang disebabkan oleh asam borat (boraks) memperlihatkan gejala batuk, iritasi mata dan mulut, dan muntah (Kumar dan Srivastava, 2011).

Menurut Madina $d k k$., (2017), penggunaan pewarna sintetik untuk pewarna tekstil seperti Rhodamin B pada makanan dan minuman, sangat berbahaya bagi kesehatan karena dapat memicu terjadinya kanker serta kerusakan ginjal dan hati. Sehubungan dengan hal tersebut, untuk menghindari dan mengurangi dampak negatif seperti tersebut di atas perlu mendapat perhatian dari insan akademis dari perguruan tinggi untuk menyampaikan penyuluhan mengenai Pengenalan Zat Aditif pada Makanan dan Dampaknya terhadap Kesehatan pada siswa dan siswi SMA Negeri 1 Belimbing Muara Enim Provinsi Sumatera Selatan dalam rangka meningkatkan kesadaran dan kesehatan masyarakat agar tercipta generasi muda yang sehat dan kuat untuk melaksanakan pembangunan bangsa.

SMA Negeri 1 Belimbing Muara Enim Provinsi Sumatera Selatan merupakan salah satu sekolah yang memiliki sarana dan prasarana yang baik dan cukup memadai. Namun keberadaannya masih jarang diketahui, dikarenakan letak sekolah berada agak dipelosok dan lokasi sekolah yang jauh dari pinggir jalan raya dan harus melewati perkebunan karet. Hal ini dibenarkan Kepala Sekolah SMA Negeri 1 Belimbing, bahwa pihak sekolah sangat jarang menerima pihak luar untuk melakukan kegiatan sosialisasi, penyuluhan ataupun kerjasama dengan SMA Negeri 1 Belimbing. Tujuan dari kegiatan PkM ini adalah untuk memberikan informasi dalam bentuk penyuluhan kepada siswasiswi khususnya kelas XII dan beberapa Guru tentang Pengenalan Zat Aditif pada Makanan dan untuk menumbuhkan kesadaran kepada siswa-siswi mengenai dampak negatif dari mengkonsumsi makanan/jajanan di sekolah yang mengandung zat aditif makanan agar masyarakat dalam hal ini siswa-siswa kelas XII sebagai senior bisa lebih mudah mengingatkan dan menjelaskan ke adik-adik kelas selain guru. Fenomena yang terjadi siswa-siswi lebih terbiasa dengan jajanan di dalam sekolah maupun di luar sekolah yang belum terjamin kesehatan makanan nya. 


\section{METODE}

Kegiatan ini dilaksanakan di Aula SMA Negeri I Belimbing Muara Enim Provinsi Sumatera Selatan. Pada tanggal 20 November 2019, dimulai dari pukul 08.00 - 12.00 WIB. Kegiatan ini menggunakan metode penyuluhan atau pemberian materi yang dilakukan dengan cara presentasi menggunakan media power point dan LCD dengan materinya meliputi Definisi dan Fungsi Zat Aditif pada Makanan, Jenis-jenis Zat Aditif pada Makanan, Dampak Positif dan Negatif Zat Aditif Makanan, Upaya Mengurangi Dampak Negatif dari Penggunaan Zat Aditif Makanan, Tinjauan Aspek Hukum Terhadap Penggunaan Zat Aditif Makanan dan Uji Kualitatif terhadap Makanan yang mengandung Zat Aditif.

Setelah pemberian materi dilanjutkan dengan melibatkan siswa/siswi dalam sesi tanya jawab terkait materi yang telah disampaikan, selanjutnya diberikan simulasi berupa lembar pertanyaan dan pemberian reward bagi 3 (tiga) siswa yang mendapatkan nilai tertinggi dalam menjawab pertanyaan.

\section{HASIL DAN PEMBAHASAN}

Kegiatan pengabdian kepada masyarakat ini diikuti oleh 10 orang guru dan 60 orang siswa/siswi kelas X11 SMA Negeri I Belimbing Muara Enim Provinsi Sumatera Selatan. Pada tahap awal kegiatan, peserta diberikan penyuluhan atau pemberian materi tentang pengenalan zat aditif pada makanan dan dampaknya terhadap kesehatan. Para siswa sangat antusias mengikuti kegiatan ini yang ditunjukkan melalui berbagai aktivitas yang disajikan pada Tabel 1 berikut ini :

Tabel 1. Aktivitas siswa-siswi selama kegiatan PkM.

\begin{tabular}{|c|l|c|}
\hline No. & \multicolumn{1}{|c|}{ Aspek yang diamati } & $\begin{array}{c}\text { Keberhasilan } \\
\text { siswa-siswi } \\
(\mathbf{\%})\end{array}$ \\
\hline 1 & Mendengarkan penjelasan & 100 \\
\hline 2 & $\begin{array}{l}\text { Terlibat dalam kegiatan } \\
\text { tanya-jawab }\end{array}$ & 16,6 \\
\hline 3 & Mengisi lembar pertanyaan & 100 \\
\hline 4 & $\begin{array}{l}\text { Ketercapaian dalam } \\
\text { menjawab pertanyaan }\end{array}$ & 86,6 \\
\hline
\end{tabular}

Hasil pengamatan pada Tabel 1 menunjukkan bahwa siswa aktif mendengarkan penjelasan tentang pengenalan zat aditif pada makanan dan dampaknya terhadap kesehatan. Keaktifan peserta kegiatan dibuktikan dengan adanya pertanyaan dari para siswa, yang mana persentase siswa yang bertanya adalah sebanyak $16,6 \%$ yaitu 10 orang dari 60 peserta, karena keterbatasan waktu sesi tanya-jawab dibatasi hanya untuk 10 pertanyaan. Adanya pertanyaan yang diajukan menunjukkan bahwa telah terjadi interaksi yang dinamis antara pemberi materi dan peserta kegiatan, serta menunjukkan adanya minat dan rasa ingin tahu yang tinggi dari peserta terhadap materi yang dibahas.



Gambar 1. Penyampaian penyuluhan oleh pemateri.

Tahap berikutnya dilanjutkan dengan diberikan simulasi berupa lembar pertanyaan. Pada tahap ini siswa antusias mengikuti dan untuk menambah semangat para siswa dalam mengisi lembar pertanyaan, pemateri telah menyiapkan 3 reward untuk siswa yang mendapatkan nilai tertinggi. Pada tahap ini berjalan tanpa kendala, para siswa dengan tertib menjawab pertanyaan sendirisendiri dengan batas waktu yang telah ditentukan. Sementara pemateri mengoreksi lembar jawaban, para siswa diajak sharing tentang kebiasaan mereka untuk jajan khususnya di lingkungan sekolah. Ditampilkan beberapa contoh makanan/minuman yang biasanya diberikan zat aditif dalam pengolahannya.



Gambar 2. Siswa-siswi mendengarkan penjelasan materi.

Persentase nilai siswa menjawab lembar pertanyaan dengan benar adalah 86,6\%. Dari 60 orang siswa yang mengikuti kegiatan. Sebanyak 52 siswa mampu menjawab dengan benar diatas 8 dari 10 soal. Diakhir kegiatan dipilih 3 (tiga) siswa yang mendapatkan nilai tertinggi dalam menjawab lembar pertanyaan untuk menerima reward. Ini menunjukkan bahwa materi yang disampaikan bisa diterima dan berhasil dipahami oleh para siswa. Sehingga dapat diartikan bahwa kegiatan ini berjalan dengan baik.

\section{KESIMPULAN}

Penyuluhan tentang pengenalan zat aditif pada makanan dan dampaknya terhadap kesehatan di SMA Negeri I Belimbing Muara Enim Provinsi Sumatera Selatan memberikan hasil yang memuaskan 
berdasarkan aktivitas tanya-jawab dan kemampuan para siswa untuk bisa menjawab lembar pertanyaan dengan benar. Hal ini memberikan arti bahwa, dengan adanya kegiatan ini memberikan dampak yang positif kepada siswa-siswi dalam memberikan informasi dan menumbuhkan kesadaran kepada siswa-siswi mengenai dampak negatif dari mengkonsumsi makanan/jajanan di sekolah yang mengandung zat aditif makanan. Diharapkan melalui kegiatan Pkm ini selanjutnya pihak sekolah dapat menghimbau dan mewajibkan jajanan dikantin sekolah maupun di sekitar sekolah untuk tidak menggunakan zat aditif pada makanan dan minuman yang dijual. Himbauan bisa melalui gambar atau poster bahaya menggunakan zat aditif pada makanan, sehingga bisa lebih menarik perhatian siswa-siswi.

\section{UCAPAN TERIMA KASIH}

Ucapan terima kasih penulis tujukan kepada semua pihak yang membantu dalam menyukseskan kegiatan pengabdian kepada masyarakat ini. Terima kasih kepada Rektor Universitas PGRI Palembang Bpk Dr. H. Bukman Lian, M.M., M.Si., Dekan FMIPA Universitas PGRI Palembang Bpk Dr. Syaiful Eddy, M.Si., Ketua LPPkM Universitas PGRI Palembang Ibu Dr. Rohana, S.Si., M.Pd dan Kepala Sekolah SMA Negeri I Belimbing Muara Enim Provinsi Sumatera Selatan Bpk. Eli Koswara, S.Pd., MM. yang telah mendanai dan memfasilitasi dalam kegiatan pengabdian kepada masyarakat ini. Terima kasih juga penulis sampaikan kepada Guru dan Siswa/siswi SMA Negeri I Belimbing Muara Enim Provinsi Sumatera Selatan yang telah berpartisipasi dan turut serta sehingga kegiatan ini dapat berjalan dengan lancar.

\section{DAFTAR PUSTAKA}

Departemen Kesehatan RI. (1992). Undang-Undang Tentang Kesehatan. Jakarta. Depkes RI. Diakses dari

www.kmpk.ugm.ac.id/images/Semester_2/Blok 1 - Sistem Kesehatan..

Departemen Pertanian. (2002). Teknologi Tepat Guna : Budi Daya Pangan. Jakarta. Diakses dari http://www.orst.edu/dept/

Downs, M. (2008). The Truth About 7 Common Food Additives. WebMD. Diakses dari www.webmd.com/.../the-truth-about-sevencommon-food-additives

Fitri, N. (2014). Butylated hydroxyanisole sebagai Bahan Aditif Antioksidan pada Makanan dilihat dari Perspektif Kesehatan. Jurnal Kefarmasian Indonesia,4(1), 41-50.

Indra, Chahaya, S. (2012, Mei 17). Bahan Tambahan Makanan, Manfaat dan Dampaknya Terhadap Kesehatan. Info Kesehatan. Diakses dari https://belantarakesehatan.blogspot.com/2012/0 5/manfaat-dan-bahaya-makanan-cepat-saji.html

Japa, L., Ahmad, R., \& Dewa, A.C.R. (2019). Pola Konsumsi Sehat dengan Memperhatikan Zat Aditif dan Nilai Gizi Bahan Makanan pada Ibu-Ibu Dan Remaja Putri Warga Rt 05 Kuburjaran Lauk Sukarara Lombok Tengah. Jurnal Pendidikan Dan Pengabdian Masyarakat, 2 (1), 17-22.

Karunia \& Finisa. B. (2013). Kajian Penggunaan Zat Adiktif Makanan (Pemanis dan Pewarna) pada Kudapan Bahan Pangan Lokal di Pasar Kota Semarang. Food Science and Culinary Education Journal. ISSN 2252-6587,2 (2), 7-78.

Kumar, G. \& N. Srivastava. (2011). Genotoxic Effects of Two Commonly Used Food Additives of Boric Acid and Sunset Yellow in Root Meristems of Trigonella

Feonumgroecum. Iran Journal Environmental Health Science Engineering,4(1), 361-366.

Madina, F.E., Rina Elvia., \& I Nyoman Chandra. (2017). Analisis Kapasitas Adsorpsi Silika Dari Pasir Pantai Panjang Bengkulu Terhadap Pewarna Rhodamine B. Jurnal Alotrop, 1(2), 98101.

Undang-Undang Republik Indonesia Nomor 18 pasal 75 ayat 1. (2012). Tentang Pangan. Diakses dari https://luk.staff.ugm.ac.id/atur/UU182012Pangan.pdf

Purnomo, M.A.J. (2017). Zat Pewarna Alam sebagai Alternatif Zat Warna yang Ramah Lingkungan. Jurnal Seni Rupa STSI Surakarta, 1(2), 57-61.

Siaka, I.M. (2009). Analisis Bahan Pengawet Benzoat Pada Saos Tomat Yang Beredar di Wilayah Kota Denpasar. Jurnal Kimia. ISSN 19079850,3(2), 87-92.

Winarno, F.G. (1992). Kimia Pangan dan Gizi. Gramedia. Jakarta.

Wisnu, Broto. (2003). Mengenal Bahan Pengawet dalam Produk Pangan Diakses dari http ://www.pom.go.id/public/publikasi/infopom120 3.pdf

Yamin, M., Jamaluddin, K., \& Nasruddin. (2018). Penyadaran Masyarakat Mengenai Dampak Negatif Penggunaan Zat Adiktif Pada Makanan Terhadap Kesehatan. Jurnal Pendidikan dan Pengabdian Masyarakat, 1(1), 44-53. 